Article

\title{
Automatic Supplement Weighing Units for Monitoring the Time of Accessing Mineral Block Supplements by Rangeland Cattle in Northern Queensland, Australia
}

\author{
Gamaliel Simanungkalit ${ }^{1, *(\mathbb{D})}$, Graeme Bremner ${ }^{1}$, Frances Cowley ${ }^{1}{ }^{(\mathbb{D}}$, Jamie Barwick ${ }^{2}$ (D), Bradley Dawson ${ }^{3}$, \\ Robin Dobos ${ }^{2,4}$ (D) and Roger Hegarty ${ }^{1}$
}

1 Ruminant Research Group (RRG), School of Environmental and Rural Science, University of New England, Armidale, NSW 2351, Australia; gbremner@une.edu.au (G.B.); fcowley@une.edu.au (F.C.); rhegart3@une.edu.au (R.H.)

2 Precision Agriculture Research Group (PARG), School of Science and Technology, University of New England, Armidale, NSW 2351, Australia; jbarwic2@une.edu.au (J.B.); robin.dobos@dpi.nsw.gov.au (R.D.)

3 Science Engineering Workshop, University of New England, Armidale, NSW 2351, Australia; bdawson@une.edu.au

4 Livestock Industries Centre, NSW Department of Primary Industries, University of New England, Armidale, NSW 2351, Australia

* Correspondence: gamasimanungkalit@gmail.com; Tel.: +61-2-6773-3929

Citation: Simanungkalit, G.; Bremner, G.; Cowley, F.; Barwick, J.; Dawson, B.; Dobos, R.; Hegarty, R. Automatic Supplement Weighing Units for Monitoring the Time of Accessing Mineral Block

Supplements by Rangeland Cattle in Northern Queensland, Australia. AgriEngineering 2021, 3, 218-229. https://doi.org/10.3390/ agriengineering 3020014

Academic Editor: Piernicola Masella

Received: 7 March 2021

Accepted: 9 April 2021

Published: 14 April 2021

Publisher's Note: MDPI stays neutral with regard to jurisdictional claims in published maps and institutional affiliations.

Copyright: (c) 2021 by the authors. Licensee MDPI, Basel, Switzerland. This article is an open access article distributed under the terms and conditions of the Creative Commons Attribution (CC BY) license (https:// creativecommons.org/licenses/by/ $4.0 /)$.

\begin{abstract}
Time spent feeding by grazing cattle is an important predictor of intake and feed efficiency. This study examined the use of automatic supplement weighing (ASW) units for monitoring voluntary access of breeding cows $(n=430)$ to mineral block supplements in an extensive rangeland of northern Australia. The ASW units $(n=10)$ were located within each of experimental sites (5 units per site; Bore and Eldons). Over the 62 days of data collection, $85 \%, 13 \%$, and $2 \%$ of cows spent $<600$, 600-1200, >1200 min accessing supplements, respectively, with between-animal variation (CV) of 107\%. A total of 133 cows visited both sites while 142 and 155 cows visited only Bore and Eldons, respectively. Most visits (80-90\%) were recorded during the day (800-1700 h), $7-17 \%$ during the night (1800-2300 h), and 3\% during the dawn (0-700 h). Time spent accessing supplements differed between ASW units across the two sites $(p<0.001)$ and varied according to the day of visits $(p<0.001)$. There was a significant relationship between time spent at the ASW units and supplement intake on a herd basis $\left(p<0.001 ; R^{2}\right.$ adj $\left.=0.70\right)$. The results showed that the ASW units were capable of monitoring access to mineral block supplements that may reflect the supplement intake of rangeland cattle.
\end{abstract}

Keywords: automatic supplement weighing (ASW) units; rangeland cattle; mineral block supplements; accessing time; supplement intake

\section{Introduction}

The extensive rangelands in northern Australia are mostly utilized for grazing by beef cattle [1]. Soils in this region are commonly mineral deficient, particularly in phosphorus (P), which affects pasture quality [2] and may severely restrict growth, reproductive success and economic performance of breeding herds [3]. Strategic supplementation of range cows with loose-licks or lick-blocks offering urea in the dry season and $\mathrm{P}$ in the rainy season is fundamental to successful cattle breeding in northern Australia [4,5]. However, the efficiency of supplement use by cattle is uncertain as some animals may not be attracted to the supplements while others that ingest supplements may exhibit a high intake variability between and within animals [6,7].

Remote monitoring and precision livestock technologies can assist producers to collect objective information on individual animals, to support better decisions for the sustainability of their cattle production system [8]. Automated technologies for measuring individual feed intake of cattle in confined situations are the Calan Gate, Insentec, 
Intergado ${ }^{\circledR}$, GrowSafe $^{\circledR}$, and SmartFeed ${ }^{\circledR}[9,10]$. In a paddock situation, the two latter systems have been tested for estimating individual mineral block supplement intake of beef cattle (e.g., [11,12]). These systems capture the Radio Frequency Identification (RFID) of individual cattle that visit the feed bin and calculate time spent feeding and supplement intake. Recent studies using the SmartFeed ${ }^{\circledR}$ system in the extensive rangelands of the US $[13,14]$ revealed that this system was capable of monitoring daily variation of supplement intake and controlling intake of individual cattle allocated to different treatments without indication of limiting individual animal intake. Since an adjustable metal framework was used to restrict access to one animal at a time [13], its application in an extensive rangeland system using a larger herd is likely to be limited by the number of cattle that can access supplements simultaneously, affecting supplement intake by competition, and the scale, remoteness and harshness of extensive grazing enterprises (e.g., [13,15]).

Conventional self-fed systems for delivering mineral block supplements for grazing cattle in the extensive rangelands of Australia only measure intake on a herd basis [5]. There is little information on between-animal variation in mineral block supplement intake for the commercial environment or associated differences in cattle performance, particularly in the tropical region of northern Australia [4]. Automated weighing systems offer the opportunity to remotely measure real-time individual intake of self-fed supplements and time spent at mineral block supplements by grazing cattle [12]. Hence, further investigations are required to assess the effectiveness of the automatic system for monitoring the intake of beef cattle in an extensive grazing system.

In a recent study, a custom-built automatic supplement weighing (ASW) unit, developed by the University of New England Science Engineering workshop, concurrently monitored mineral block disappearance and time spent at the unit by cattle [15]. This small-scale study used 112 cattle-offered mineral block supplements through an ASW unit in a 32-ha paddock. Although the quantification of the supplement intake was measured on a herd basis, daily time spent at the ASW unit by cattle was proportional to supplement disappearance. Unlike other commercially available systems, the ASW unit used in this experiment offers the potential to improve cost efficiency as it allows multiple cattle to access the mineral block supplement simultaneously. However, the effectiveness of the system to deliver mineral block supplements for range cattle has hitherto not been reported. Hence, this current study examined the use of ASW units to monitor access to mineral block supplements by breeding cows in an extensive rangeland region of northern Australia.

\section{Materials and Methods}

The study was conducted at Burleigh station ( $20^{\circ} 03^{\prime} 18^{\prime \prime} \mathrm{S} 143^{\circ} 09^{\prime} 16^{\prime \prime} \mathrm{E} ; \sim 314 \mathrm{~m}$ altitude) in the southern Gulf of Carpentaria near Richmond, Queensland, Australia (Figure 1). The experimental procedures and use of animals were approved by the University of New England's Animal Ethics Committee (AEC18-047) in accordance with the "Australian Code for the Care and Use of Animals for Scientific Purposes".

\subsection{Animals and Experimental Sites}

A total of 430 mature Bos indicus (Brahman) based cows (mean \pm SD; $453 \pm 70 \mathrm{~kg}$ body weight) grazed a 7615-ha paddock for 93 days throughout the latter part of the dry season (11 August-11 November 2019). Each cow was fitted with an RFID tag (Allflex ${ }^{\circledR}$ Pty Ltd., Capalaba, Queensland, Australia) attached to the right ear. Within the paddock, the two experimental sites comprised fenced yards $\left(14,000 \mathrm{~m}^{2}\right.$ per yard) providing water [sites; Bore $\left(20^{\circ} 00^{\prime} 16^{\prime \prime} \mathrm{S} 143^{\circ} 02^{\prime} 20^{\prime \prime} \mathrm{E}\right)$ and Eldons $\left.\left(20^{\circ} 03^{\prime} 10^{\prime \prime} \mathrm{S} 143^{\circ} 00^{\prime} 22^{\prime \prime} \mathrm{E}\right)\right]$ while other water sources were fenced-off. The linear distance between the two sites was $6350 \mathrm{~m}$. In 2019, the annual rainfall for the nearest town (Richmond) was $502 \mathrm{~mm}$, with average monthly temperatures $\left({ }^{\circ} \mathrm{C}\right.$ ) and relative humidities (\%) of $19.2{ }^{\circ} \mathrm{C}, 27.5 \%$ (August); $23.9{ }^{\circ} \mathrm{C}, 20.5 \%$ (September); $28.2^{\circ} \mathrm{C}, 18.0 \%$ (October); and $31.5^{\circ} \mathrm{C}, 19.0 \%$ (November) (Australian Bureau of Meteorology, accessed 16th August 2020). Major pasture species in the paddock were wiregrass (Aristida spp.) with conkerberry (Carissa lanceolata R.Br.) as a dominant shrub 
species. Pasture quality and composition in this area has been described by Hall et al. [16]. Before the experiment commenced, cows were subjected to an eight-week adaptation period to become familiar with the ASW units.

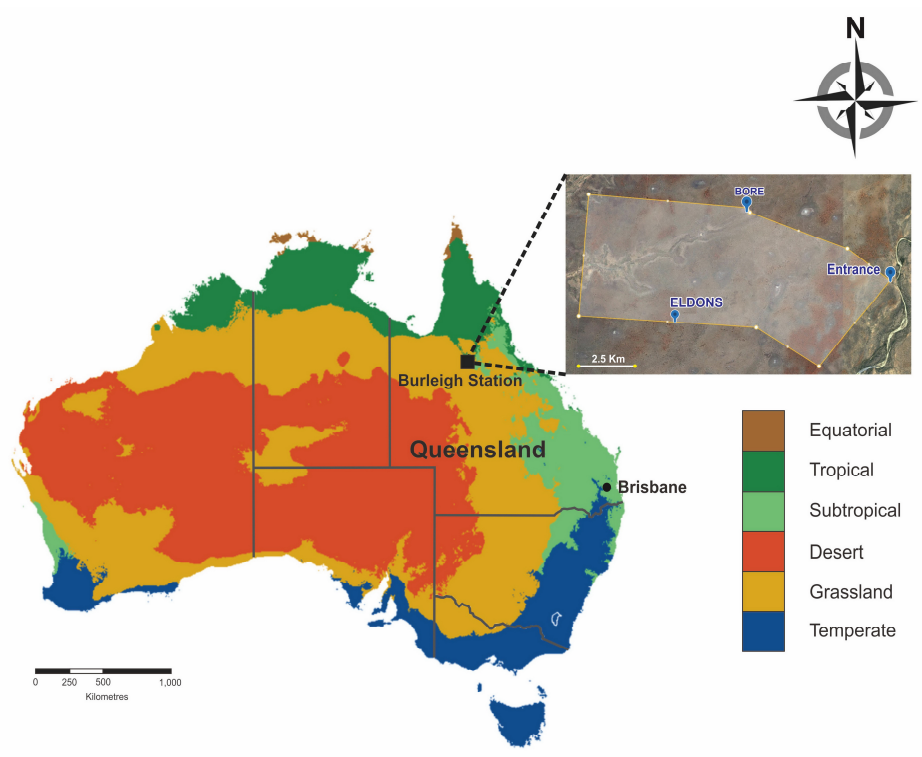

Figure 1. Location of Burleigh station showing where the automatic supplement weighing (ASW) units were placed within the experimental sites.

\subsection{Automatic Supplement Weighing Units}

Use of the ASW unit to estimate supplement intake of grazing cattle has been briefly described by Simanungkalit et al. [15]. However, the ASW units used in this current study (Figure 2) integrated a built-in Wi-Fi to transmit the data instead of a 3G modem. The ASW unit identified cows by reading their National Livestock Identification System (NLIS) compliant RFID ear-tag using the RFID panel reader. It incorporated a 4-channel multiplexer, 4 RFID reader antennas, an antenna tuning circuitry, and a TIRIS HDX $134 \mathrm{kHz}$ RFID reader (Forty Trout Electronic ${ }^{\circledR}$ Pty Ltd., Melbourne, Victoria, Australia). When a cow approached the ASW unit at a maximum distance of $50 \mathrm{~cm}$, an antenna recorded the RFID twice and then the multiplexer switched to the next antenna which recorded twice and the process continued through the four antennas. The time spent at each antenna is $150 \mathrm{msec}$, so with a 4-channel multiplexer, each RFID is read every $600 \mathrm{msec}(0.6 \mathrm{~s})$ when the RFID is in the range.

The supplement weighing platform $(1.2 \mathrm{~m}$ length $\times 1.2 \mathrm{~m}$ width) mounted on two load bars (weigh beams) (KWB 600i, Kelba ${ }^{\circledR}$ Pty Ltd., Hornsby, New South Wales, Australia) supported a maximum load of $2000 \mathrm{~kg}$. The weighing platform holding the supplements was monitored constantly by a weight indicator (R320; Rinstrum ${ }^{\circledR}$ Pty Ltd., Brisbane, Queensland, Australia). Data from the weight indicator was downloaded via an RS-232 serial cable through a RS-232 to USB converter to a USB port on a single board computer (Raspberry Pi; RS Components ${ }^{\circledR}$ Pty Ltd., Hornsby, New South Wales, Australia), which constantly monitored input from the USB ports. When detecting an RFID, the weight reading was recorded and time-stamped. Data was then written to file and each reading transmitted through the internet Wi-Fi connection to a server in the Information Technology Directorate at UNE (Figure 3). 


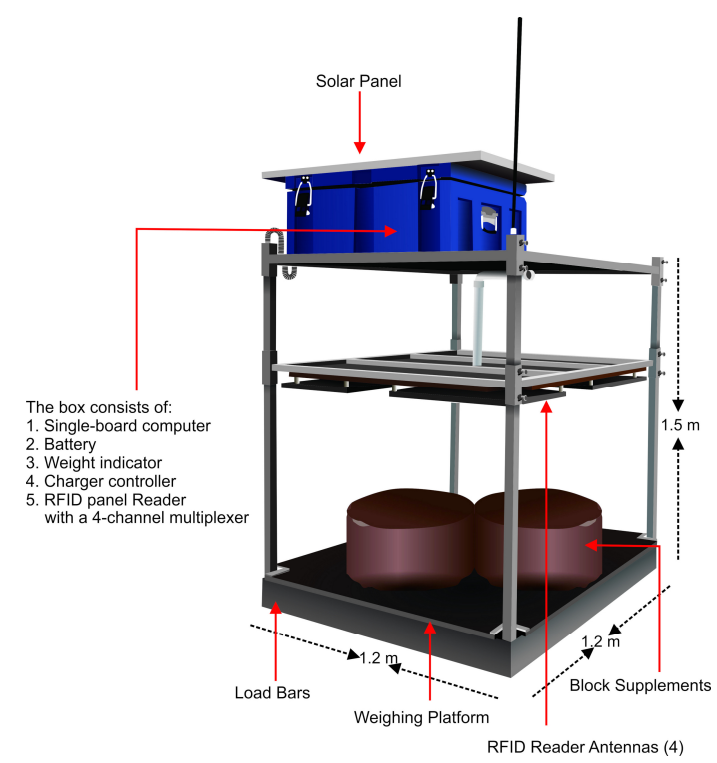

Figure 2. The layout of the automatic supplement weighing (ASW) unit.

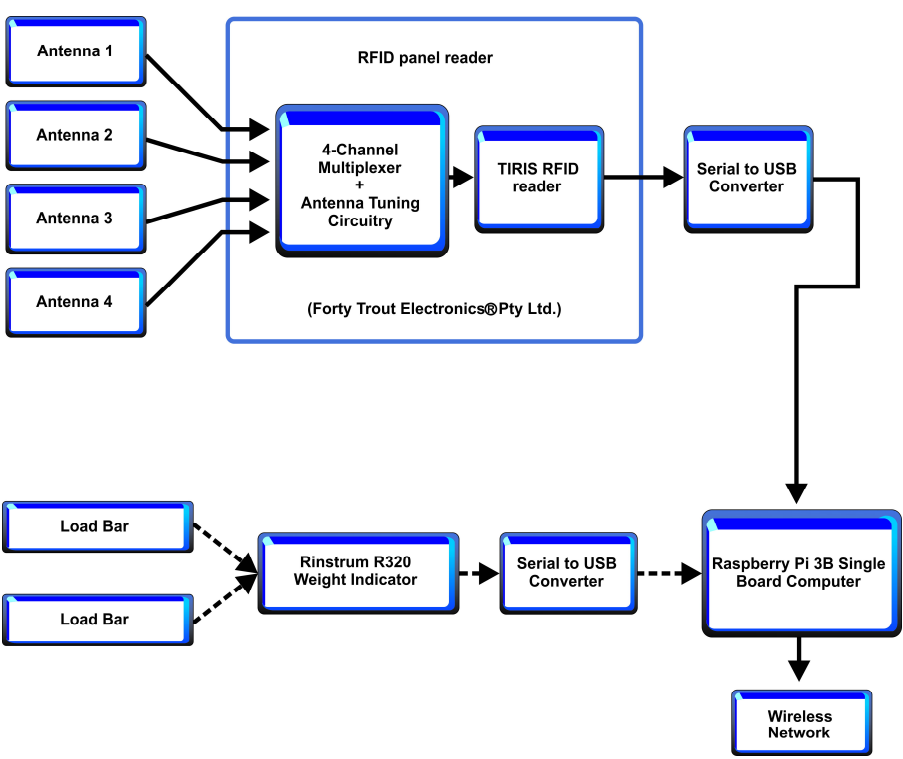

Figure 3. Schematic of the automatic supplement weighing (ASW) unit hardware.

\subsection{Experimental Procedures}

Each site was equipped with an auto-drafter gate (entrance) and four spear gates (exits), and three water troughs and five ASW units. A walk-over weighing (WoW) unit (Tru-Test Remote WoW; Tru-Test ${ }^{\circledR}$ by Datamars Australia Pty Ltd., Banyo, Queensland, Australia) was installed at the entrance gate, to record real-time body weights of individual cattle accessing mineral block supplements and water. The mineral block supplements were custom-manufactured (Olsson Industries Pty Ltd., Morningside, Queensland, Australia) containing urea $(40 \%)$, sulphur $(12 \%)$, phosphorus $(12 \%)$, and vitamin D $(1.25 \% 25 \mathrm{OHD} 3$; Hy-D ${ }^{\circledR}$, DSM Nutritional Products, Wagga Wagga, N.S.W., Australia). Mineral blocks of $100 \mathrm{~kg}$ were placed on the ASW units' weighing platforms, so that the presence of cows at the blocks could be detected by the ASW units. The WoW and ASW units were calibrated with a $400 \mathrm{~kg}$ load at commencement.

Each site was fenced into two yards, being Draft 0 (100 m length $\times 35 \mathrm{~m}$ width), equipped with water trough only, and Draft 1 (100 m length $\times 105 \mathrm{~m}$ width) in which the ASW units were also located (Figure 4). Cattle with no RFID tags or those whose RFID 
ear-tag numbers were not recognized by the auto-drafter were directed to Draft 0 . Over 93 days of the experimental period, all cows had a 62-day free access to both sites and all ASW units. Initial body weight data were calculated from WoW records for the week before commencing the experiment. While data were considered for 430 cows, a small number of cattle (bulls and calves) without RFID ear-tags were likely to also be present in the paddock because of incomplete mustering.

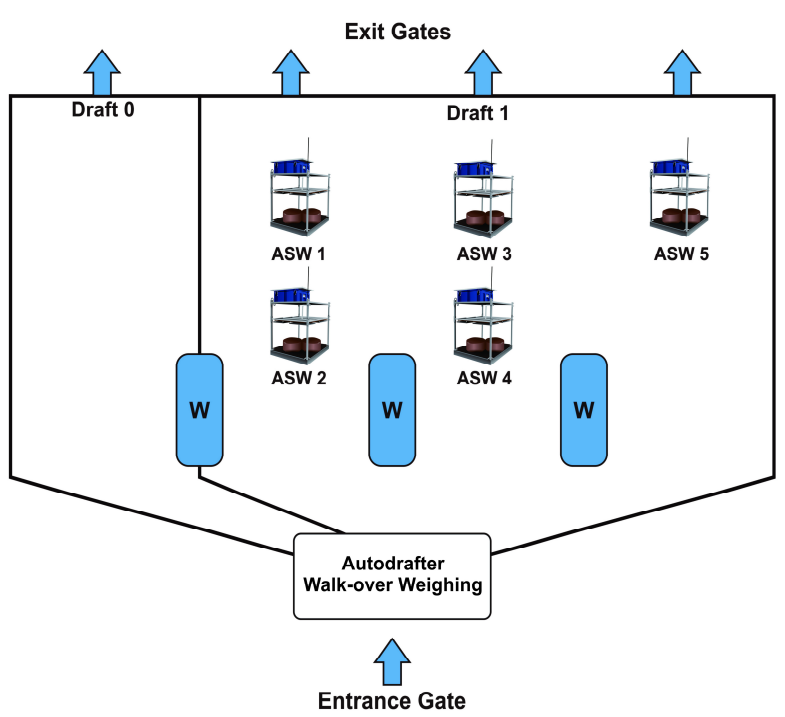

Figure 4. The layout of the experimental sites where the automatic supplement weighing (ASW) units, water troughs $(\mathrm{W})$, and walk-over weighing were installed on each site. The total area of Draft 0 and Draft 1 was 3500 and 10,500 $\mathrm{m}^{2}$, respectively.

\subsection{Data Processing and Analysis}

The Structured Query Language (SQL) (Oracle ${ }^{\circledR}$ Corporation, Redwood Shores, CA, USA) for relational database management systems (RDBMS) was used to retrieve the data from the UNE database server onto a personal computer in a comma-separated values (.csv) format. The raw data containing inaccurate RFID readings and low recording data (<100 records) over the 62 days of data collection were screened using Microsoft Excel 2016 (version 16.0, Microsoft Corporation, Washington, DC, USA) and the dplyr package [17] of $\mathrm{R}$ statistical software [18]. The $\mathrm{R}$ software was also used to summarise and visualise the data. The number of rows containing RFID represented the number of visits to the ASW units. As one record equated to $0.6 \mathrm{~s}$, time spent (duration) at each ASW unit by individual cattle (min) was computed by dividing the number of records by 100 .

Before further analysis, distribution of the data for time spent at the ASW units were verified using the Shapiro-Wilk test. Since the data were not normally distributed, logarithmic transformation was applied. To compare the mean difference of time spent accessing mineral block supplements by cows between the ASW units, a linear mixedeffects model was performed using lmerTest package of $R$ statistics [19]. The statistical model was:

$$
\mathrm{Y}_{\mathrm{ijk}}=\mu+\mathrm{ASW}_{\mathrm{i}}+\mathrm{Day}_{\mathrm{j}}+\mathrm{Cow}_{\mathrm{ijk}}+\varepsilon_{\mathrm{ijk}}
$$

where $Y_{i j k}$ is time spent by Cow $k$ at day $j$ in the ASW unit $i, \mu$ is the overall mean, ASW $_{i}$ is a fixed effect ( $i=1$ to 10$),$ Day $_{j}$ is a fixed effect $(j=1$ to 62$), \operatorname{Cow}_{i j k}$ is a random effect on Cow $\mathrm{k}$ at day $\mathrm{j}$ in the ASW unit $\mathrm{i}$, and $\varepsilon_{\mathrm{ijk}}$ is random error on Cow $\mathrm{k}$ at Day $\mathrm{j}$ in the ASW unit $\mathrm{i}$.

Association between time spent accessing the ASW units and mineral block supplement intakes was validated using a simple linear regression model. Data from the ASW 
unit with the highest daily RFID records was sampled from each site every day for 62 days $(n=124)$. The statistical model was:

$$
Y_{i}=\beta_{0}+\beta X_{i}+\varepsilon_{i}
$$

where $Y_{i}$ is cumulative daily time spent at the ASW units by herd, $X_{i}$ is total mineral block supplement disappearance, $\varepsilon_{\mathrm{i}}$ is the random error, and $\mathrm{i}=1$ to 124 .

\section{Results}

\subsection{Time Spent at the Automatic Supplement Weighing Units}

Across 93 days of observation, there were 31 days where access to all ASW recordings on both sites was restricted because of lost or unstable Wi-Fi connectivity. Six cows were removed from the analysis because of incorrect RFID readings and less than 100 ( $1 \mathrm{~min})$ records. There were 12,630,200 (126,302 $\mathrm{min}$ ) RFID recordings retrieved from $10 \mathrm{ASW}$ units across the two experimental sites over 62 days of data collection. Figure 5 shows the frequency distribution of cumulative time spent by individual cows at the ASW units over 62 days of data collection. Of 430 cows, $85 \%$ of them spent $1-600 \mathrm{~min}, 13 \%$ spent $600-1200 \mathrm{~min}$, and $2 \%$ spent $>1200 \mathrm{~min}$ at the ASW units. Over the 62 days, on average each cow visited an ASW unit on 23 days $(C V=57 \%)$, spending a total of $294 \mathrm{~min}(\mathrm{CV}=107 \%)$ at the ASW units.

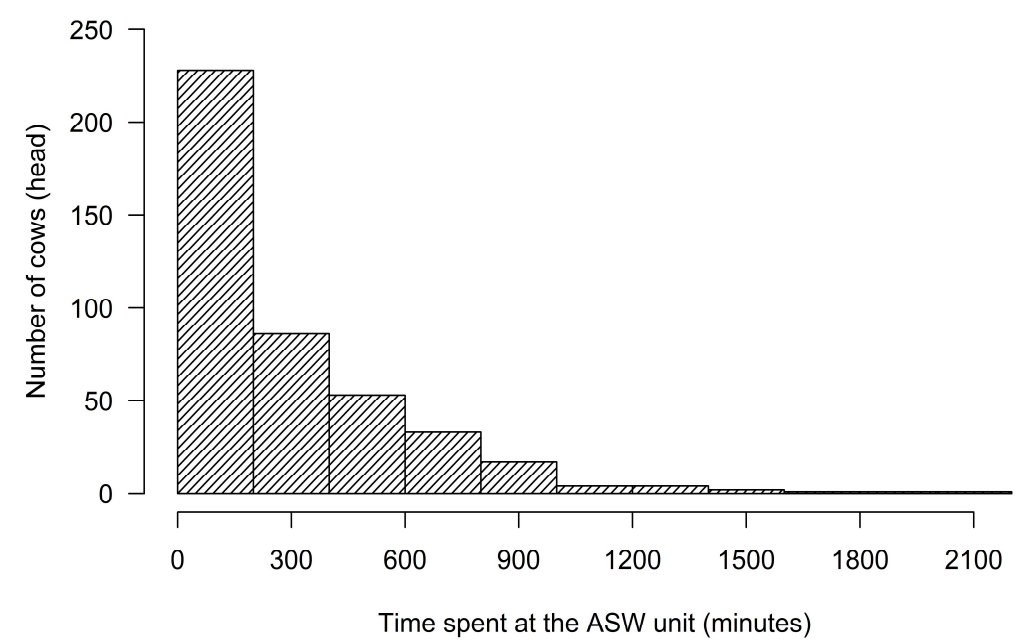

Figure 5. Frequency distribution of cumulative time spent by 430 cows accessing the automatic supplement weighing (ASW) units over 62 days of data collection.

\subsection{Number of Cows and Individual Time Spent Accessing the Sites}

Table 1 shows descriptive statistics of the number of cows accessing each site and the cumulative time spent by individual cows at the ASW units over the 62 days of data collection. Although the 430 cows had free access to both sites, only $31 \%$ (133) of them visited both sites, whereas the remaining 33\% (142) and 36\% (155) visited only Bore or Eldons sites, respectively. Total times spent at the ASW units by these three groups of cows were $42,957.4 \mathrm{~min}$ (both sites), 39,311.2 $\mathrm{min}$ (Bore only), and 44,033.5 min (Eldons only), with between-animal variability $(\mathrm{CV})$ of $107 \%, 108 \%$, and $106 \%$, respectively. 
Table 1. Summary statistics of the total time spent at the automatic supplement weighing (ASW) units by individual cows over 62 days of data collection.

\begin{tabular}{|c|c|c|c|c|c|c|}
\hline & \multicolumn{6}{|c|}{ Experimental Sites } \\
\hline & \multicolumn{2}{|c|}{ Bore + Eldons } & \multicolumn{2}{|c|}{ Bore } & \multicolumn{2}{|c|}{ Eldons } \\
\hline & CTS (min) & $n$-Day ${ }^{2}$ & CTS (min) & $n$-Day ${ }^{2}$ & CTS (min) & $n$-Day ${ }^{2}$ \\
\hline$n^{1}$ & \multicolumn{2}{|c|}{133} & \multicolumn{2}{|c|}{142} & \multicolumn{2}{|c|}{155} \\
\hline Minimum & 4.9 & 4 & 2.2 & 1 & 2.7 & 1 \\
\hline Maximum & 2047.3 & 51 & 1547.4 & 60 & 1675.8 & 50 \\
\hline Median & 201.7 & 27 & 178.2 & 30 & 169.3 & 20 \\
\hline Mean & 323.0 & 25 & 276.8 & 29 & 284.1 & 19 \\
\hline SD & 345.17 & 13.1 & 299.24 & 13.7 & 301.68 & 11.2 \\
\hline
\end{tabular}

${ }^{1} 1$ Number of cows that visited the site(s) over 62 days; ${ }^{2}$ Number of days recorded for each individual across 430 cows over 62 days; CTS = cumulative time spent at the ASW units for each individual across 430 cows over 62 days; $\mathrm{SD}=$ standard deviation.

\subsection{Visiting Time of Cows to the Sites and Automatic Supplement Weighing Units}

Throughout the 62 days of data collection, Bore site captured 6,884,927 of RFID records $(68,849.3 \mathrm{~min} ; 54.5 \%)$ whereas the Eldons site captured 5,745,273 (57,452.7 $\mathrm{min} ; 45.5 \%)$ of RFID records. Figure 6 shows that most visits to ASW units occurred during the daylight hours. Visits to ASW units recorded between $800-1700$ h were $80 \%$ for Bore site and $90 \%$ for Eldons site, respectively. Approximately $17 \%$ (Bore) and/or 7\% (Eldons) of visits to ASW units were recorded during the night time (1800-2300 h) and only $3 \%$ of visits occurred during the dawn $(0-700 \mathrm{~h})$ for both sites.
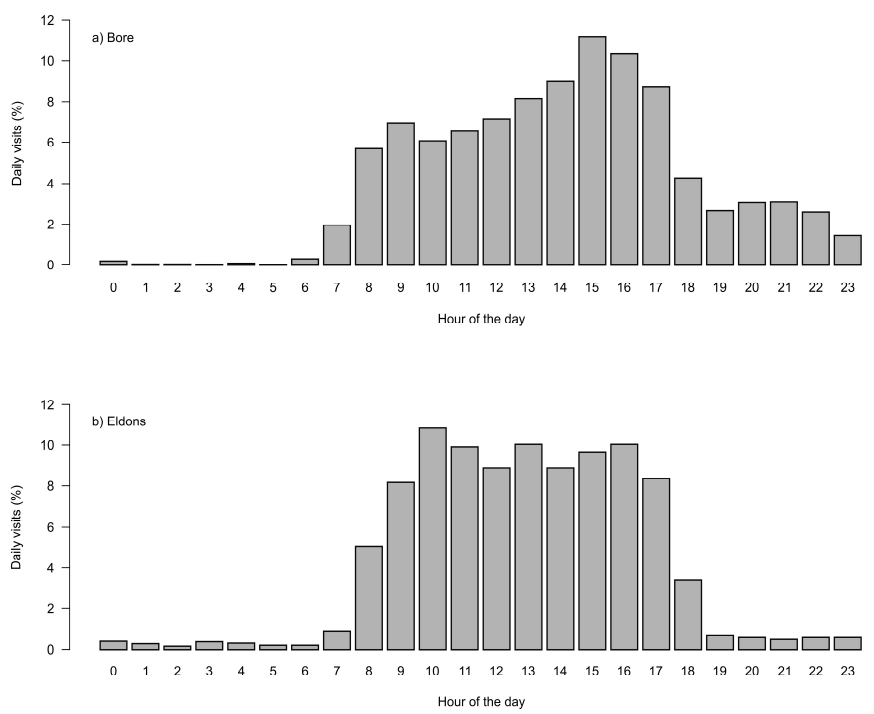

Figure 6. Frequency distribution of time of the visit to the automatic supplement weighing (ASW) units over a 24-h period in (a) Bore and (b) Eldons sites.

Time spent accessing mineral block supplements by individual cows was considerably different between ASW units ( $p<0.001$ ), except for ASW 1 (Bore) vs ASW 4 (Bore), ASW 4 (Eldons) vs ASW 5 (Eldons), and ASW 2 (Bore) vs ASW 4 (Eldons) (Table 2). There was a significant difference in time spent at the ASW units between days of data collection $(p<0.001)$. Over 62 days, the average individual time spent at an ASW unit ranged from 0.1 to $10 \mathrm{~min} /$ day with the CV ranging between $112 \%$ and $198 \%$. 
Table 2. Average daily time spent at the automatic supplement weighing (ASW) units (mean \pm SD) by individual cows across two sites over 62 days of data collection.

\begin{tabular}{lcccccc}
\hline \multirow{2}{*}{ Sites } & \multicolumn{5}{c}{ Time Spent at the ASW Units (min/day) $^{\mathbf{1}}$} & \multirow{2}{*}{ p-Value } \\
\cline { 2 - 6 } & ASW 1 & ASW 2 & ASW 3 & ASW 4 & ASW 5 & \\
\hline Bore & $10.7 \pm 14.9^{\mathrm{a}}$ & $7.1 \pm 14.1^{\mathrm{b}}$ & $8.7 \pm 14.4^{\mathrm{c}}$ & $6.7 \pm 8.7^{\mathrm{ad}}$ & $3.7 \pm 5.5^{\mathrm{e}}$ & \\
Eldons & $28.9 \pm 36.7^{\mathrm{f}}$ & $8.9 \pm 12.1^{\mathrm{g}}$ & $1.6 \pm 3.1^{\mathrm{h}}$ & $4.8 \pm 9.2^{\mathrm{bi}}$ & $0.1 \pm 0.1^{\mathrm{ij}}$ & $<0.001$ \\
\hline
\end{tabular}

${ }^{1}$ means that share similar superscript letters across rows and columns are not significantly different $(p>0.05)$.

\subsection{Relationship between Time Spent at the ASW Units and Mineral Block Intakes}

Data from the two ASW units (one per site) with the highest daily RFID records over the 62 days of data collection were interrogated to establish relationships between time spent at the unit and mineral block supplement intake. The average number of cows and time spent visiting the ASW unit was 42 head/day $(\mathrm{CV}=45 \%)$ and $336 \mathrm{~min} /$ day $(\mathrm{CV}=69 \%)$, respectively, where the total mineral block supplement disappearance was averaged $5594 \mathrm{~g} /$ day $(C V=77 \%)$. Daily cumulative time spent at an ASW unit (x) and mineral block supplement disappearance (y) within the same day were significantly correlated (Adjusted $\mathrm{R}^{2}=0.70$; RMSE $=2234 \mathrm{~g} ; p<0.001$ ) (Figure 7).

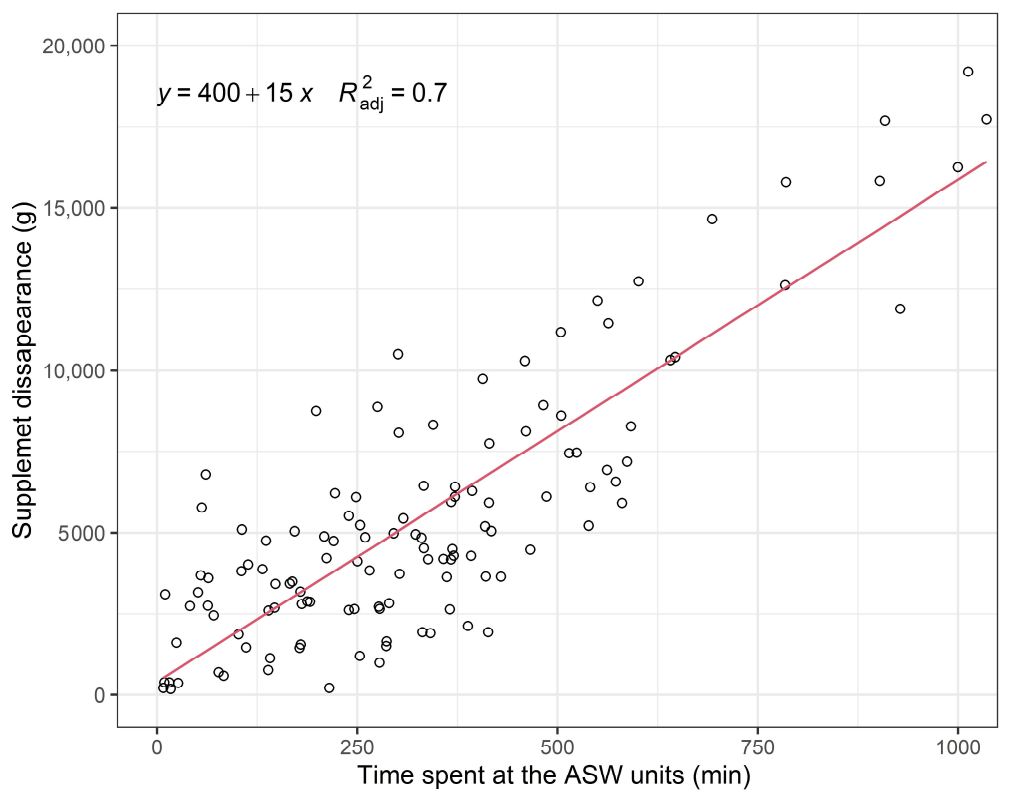

Figure 7. Relationship between mineral block supplement disappearance and time spent at the automatic supplement weighing (ASW) units by the herd across two sites over 62 days of data collection. The regression line shows a trend.

\section{Discussion}

Application of remote monitoring using internet technology in the beef cattle industry is increasing, particularly for monitoring body weight, feed intake, and physiological status of the animals $[15,20]$. Providing supplemental feeds for breeding cows in the extensive rangeland of northern Australia is pivotal since the lack of dietary nutrients, particularly nitrogen in the dry season and $\mathrm{P}$ in the wet season, is apparent [2,4]. Voluntary intake of self-fed supplements by grazing cattle is primarily contingent upon the physiological condition of the animals and attractiveness of the supplements [21]. In this study, the RFID system in conjunction with a single-board computer and internet technology integrated into the ASW units was capable of remotely monitoring time of access and time spent at mineral block supplements as well as predicting mineral block supplement intake by rangeland cattle. By making these simple units at modest cost (approximately AU\$ 8000/unit), the individual daily intake of supplement by each animal could be estimated, with a potential 
for multiple ASW units being used to deliver multiple different blocks in replicated trials as has been done subsequently.

The RFID technology in the beef cattle production system serves as a tool to improve efficiency and productivity [22]. Autonomous RFID records were successful at monitoring visits and interval times of grazing cattle to water points [23]. In our study, however, there were $31(33 \%)$ days where the sites were inaccessible because of the quality of internet connection. This is mostly due to the automatic gate setting that could allow the animal to access Draft 0 only, with no ASW unit if the internet connection was poor. A previous experiment using similar equipment in a smaller paddock had 41 consecutive days of experiment because of the availability of $3 G$ connection [15]. In this current study, the internet connection was relayed using a custom-built Wi-Fi antenna whose stability was affected by harsh environmental conditions such as dust and extreme temperature. Williams et al. [20] pointed out that maintaining continuous connectivity is the greatest challenge in installing electronic equipment in an extensive environment. Hence, regular facility maintenance is required for a long-term operation.

Some ASW units in this current study may have failed to send the data because of several issues. The RFID tags used in this current study were manufactured by Allflex. An experiment in feedlot cattle by Wallace et al. [24] reported $>95 \%$ readability of Allflex HDX RFID ear-tags by panel readers, which was superior to other commercially available RFID brands. However, Williams et al. [23] stated that malfunction of the RFID systems prevented the panel reader to transmit a signal to the data logger due to power disruption, broken communication cables, and insufficient data logger memory. Ruiz-Garcia et al. (2011) [22] contended that RFID application in an extensive grazing environment requires longer reading because forage canopies could potentially weaken the signal strength. False readings may be attributed to physical properties of RFID tags causing electromagnetic wave distortion by materials containing metals and liquids that can hinder the transmission of the waves, especially for UHF and microwave frequencies [25].

The ASW unit records indicated that between-animal variation of cumulative time spent accessing mineral block supplements over 62 days was 107\%. Imaz et al. [12] reported a significant relationship between individual daily time spent at Smartfeed ${ }^{\circledR}$ feeder and mineral block supplement intake $(p<0.01)$ with an $80 \% \mathrm{CV}$ of between-animal variability. The number of cattle, the type and number of automatic feeders, and the extent of paddocks and watering points between these studies might contribute to the differences in results. However, Imaz et al. [12] inferred that mineral block intake variation was mostly influenced by individual behaviour rather than the whole herd. Sowell et al. [26] explained that social hierarchies in a herd cause most issues in providing supplement for grazing cattle. For instance, subordinate cattle may access less supplements than do the dominant cattle causing high between-animal intake variability because of over-consumption of supplements by the dominant animals.

Most visits to ASW units took place during the daylight hours between 0800 and $1700 \mathrm{~h}$. This is in agreement with Cockwill et al. [11] and Reuter et al. [13] who revealed that visits to automatic feeders containing molasses blocks peaked between 1000 and $1500 \mathrm{~h}$. Likewise, Tait et al. [27] stated that nearly $50 \%$ of visits to molasses block supplements occurred in the late afternoon $4 \mathrm{~h}$ before sunset. In the current study, water was only available at the two sites, and cattle would have been attracted to mineral blocks on the adjacent ASW units after drinking. Time of visits to mineral block supplements mostly occurred between sunrise and sunset and was relatively comparable to Williams et al. [23] who reported time of water point visit by beef cattle in a similar environment. This is because water points' position in this current study was adjacent to the ASW units, causing voluntary access to mineral block supplement to be highly influenced by water point use by cows. However, some cows visited during the night, particularly at the Bore site. This is in line with Tait et al. [27], who reported that visits to water and free-choice mineral supplements peaked at $2200 \mathrm{~h}$, with these behavioural patterns influenced by light intensity and temperature. In a milder climate, Kilgour [28] explained that ruminating and resting 
mostly occurred at night while the diurnal rhythm of grazing and feeding activities was driven by sunlight.

Failure of the ASW system to capture the presence of ear-tagged cows was likely the cause of the significant discrepancies among the ASW units across the two sites $(p<0.001)$. In the GrowSafe ${ }^{\circledR}$ system, Schwartzkopf-Genswein et al. [25] reported that interference from external radio frequency such as citizen band radio and the satellite was responsible for the failure of the system in registering attendance of cattle. The ungrounded ASW unit metal frame is a factor that could potentially disrupt the radio wave transmission. Resonation of the ASW unit metal frame may act as an antenna and hamper the detection of the RFID transponder by the panel reader. Orientation of the RFID to the reader antennas can also affect the detection of the transponders by the system. SchwartzkopfGenswein et al. [25] explained that the maximum range of detection can be achieved if the RFID transponder is in line with the antenna. Apart from these technical issues, individual preference for particular mineral block units may explain the higher visit frequencies for ASW 1 at both sites, which would have contributed to between-animal intake variations. In range cattle, Wesley et al. [29] explained that behavioural syndrome or behaviour variations between individuals was consistently occurring within and across situations [29]. The difference in individual preference for a particular mineral block might be associated with the personality of the individual, such as explorative behaviour, reactivity, sociability, social environment [30], and competition for the supplement [7].

The association between mineral block intake and time spent at the ASW units $\left(R^{2}\right.$ Adj $\left.=0.70\right)$ was lower than in the study by Simanungkalit et al. $(2020)[15]\left(R^{2}=0.93\right)$ and by Imaz et al. (2020) [12] $\left(R^{2}=0.90\right)$. In addition, the error percentage of the linear association (\%RMSE) was higher than that of the previous study [15] ( $42 \%$ vs $34 \%$ ). These might have been due to the greater number of cattle used and non-feeding activities being counted as feeding. Schwartzkopf-Genswein et al. [25] reported that $84 \%$ of the total attendance to the GrowSafe ${ }^{\circledR}$ feeder was spent in the act of feeding. By using the Intergado ${ }^{\circledR}$ system, Oliveira et al. [10] found a long-term visit duration by multiple cattle was interpreted by the system as a single long-term visit by one animal. In this current study, up to six cows could potentially approach the ASW units concurrently. This social interaction might increase non-feeding activities which the ASW units counted as feeding events.

The presence of multiple animals could also potentially confound the ASW system registering to the RFID transponder, associated with variable power demand and supply from solar panels to the computer. Vujović et al. [31] stated that power consumption of Raspberry-Pi fluctuates depending on the number of tasks. Hence, more animals present at the ASW unit would increase power consumption. While this rarely occurred, the computer might fail to record the RFID during sustained high activity at the ASW units, coinciding with overcast weather and slow recharge, resulting in low battery voltage and system failure. Apart from technical issues, the ASW units were capable of monitoring time of accessing and time spent at the units that reflected the voluntary access to mineral block supplement. Real-time information of time of accessing supplement, number of cows that voluntarily access supplement, and supplement intake provided by the ASW units could assist graziers to better understand management practice in providing supplemental feeds for breeding cows in an extensive rangeland, particularly to determine the optimal amount and distribution of supplement offered.

\section{Conclusions}

This study has shown that the ASW units successfully monitored access to mineral block supplements by breeding cattle in an extensive rangeland environment. A significant relationship between time spent at the ASW unit and mineral block intake on a herd basis indicated the accuracy of the ASW unit for the prediction of individual supplement intake. Diurnal and spatial behavioural patterns were observed, although between- and withinanimal variability was high. A difference in time spent accessing mineral block supplements by cows between the ASW units across the two sites was partly attributable to failure of 
the system to capture attendance of cattle because of technical issues such as unstable internet connection and interference from external radio waves. Hence, improvement in the infrastructure, particularly increasing resilience of the internet connection in a harsh environment, is required for maintaining continuous operation to obtain more accurate and reliable data in a long-term observation.

Author Contributions: Conceptualization, G.S. and R.H.; methodology, G.S., R.H. and R.D.; software, G.S., G.B., B.D. and R.D.; validation, F.C. and J.B.; formal analysis, G.S. and R.D.; investigation, R.H. and J.B.; resources, G.B. and B.D.; data curation, G.S. and G.B.; writing-original draft preparation, G.S.; writing-review and editing, R.H., J.B., F.C. and R.D.; visualization, G.S.; supervision, R.H., F.C., and J.B.; project administration, R.H. and G.B.; funding acquisition, R.H. All authors have read and agreed to the published version of the manuscript.

Funding: This research is funded by the Meat \& Livestock Australia (MLA) Donor Company through Livestock Productivity Partnership (LPP) as part of Project “Optimising supplement use in Australia's northern beef industry" (P.PSH.0857). The first author is supported by the Australian Government through Endeavour Postgraduate Leadership Award (PhD). Olsson Industries and AJM Pastoral are thanked for supporting the project.

Institutional Review Board Statement: The study was conducted according to the guidelines of the Australian Code for the Care and Use of Animals for Scientific Purposes, and approved by University of New England's Animal Ethics Committee (AEC18-047 30/06/2018).

Informed Consent Statement: Not applicable.

Data Availability Statement: The data presented in this study are available upon request from the corresponding author.

Acknowledgments: Daniel Watkins from UNE Information Technology Directorate is thanked for his technical assistance.

Conflicts of Interest: The authors declare no conflict of interest.

\section{References}

1. Hunt, L.P.; McIvor, J.G.; Grice, A.C.; Bray, S.G. Principles and guidelines for managing cattle grazing in the grazing lands of northern Australia: Stocking rates, pasture resting, prescribed fire, paddock size and water points-A review. Rangeland J. 2014, 36, 105-119. [CrossRef]

2. McIvor, J.G.; Guppy, C.; Probert, M.E. Phosphorus requirements of tropical grazing systems: The northern Australian experience. Plant Soil 2011, 349, 55-67. [CrossRef]

3. Bowen, M.K.; Chudleigh, F.; Dixon, R.M.; Sullivan, M.T.; Schatz, T.; Oxley, T. The economics of phosphorus supplementation of beef cattle grazing northern Australian rangelands. Anim. Prod. Sci. 2020, 60, 683-693. [CrossRef]

4. Dixon, R.M.; Anderson, S.T.; Kidd, L.J.; Fletcher, M.T. Management of phosphorus nutrition of beef cattle grazing seasonally dry rangelands: A review. Anim. Prod. Sci. 2020, 60, 863-879. [CrossRef]

5. Eggington, A.R.; McCosker, T.H.; Graham, C.A. Intake of lick block supplements by cattle grazing native monsoonal tallgrass pastures in the Northern Territory. Rangeland J. 1990, 12, 7-13. [CrossRef]

6. Dixon, R.M.; White, A.; Fry, P.; Petherick, J.C. Effects of supplement type and previous experience on variability in intake of supplements by heifers. Aust. J. Agric. Res. 2003, 54, 529-540. [CrossRef]

7. Bowman, J.G.P.; Sowell, B.F. Delivery method and supplement consumption by grazing ruminants: A review. J. Anim. Sci. 1997, 75, 543-550. [CrossRef]

8. Norton, T.; Chen, C.; Larsen, M.L.V.; Berckmans, D. Precision livestock farming: Building 'digital representations' to bring the animals closer to the farmer. Animal 2019, 13, 3009-3017. [CrossRef]

9. Culbertson, M.M. Genetic Selection for Feed Intake and Efficiency in Beef Cattle. Ph.D. Thesis, Colorado State University, Fort Collins, CO, USA, 2019.

10. Oliveira, B.R.; Ribas, M.N.; Machado, F.S.; Lima, J.A.M.; Cavalcanti, L.F.L.; Chizzotti, M.L.; Coelho, S.G. Validation of a system for monitoring individual feeding and drinking behaviour and intake in young cattle. Animal 2018, 12, 634-639. [CrossRef]

11. Cockwill, C.L.; McAllister, T.A.; Olson, M.E.; Milligan, D.N.; Ralston, B.J.; Huisma, C.; Hand, R.K. Individual intake of mineral and molasses supplements by cows, heifers and calves. Can. J. Anim. Sci. 2000, 80, 681-690. [CrossRef]

12. Imaz, J.A.; García, S.; González, L.A. Application of in-paddock technologies to monitor individual self-fed supplement intake and liveweight in beef cattle. Animals 2020, 10, 93. [CrossRef]

13. Reuter, R.R.; Moffet, C.A.; Horn, G.W.; Zimmerman, S.; Billars, M. TECHNICAL NOTE: Daily variation in intake of a salt-limited supplement by grazing steers. Prof. Anim. Sci. 2017, 33, 372-377. [CrossRef] 
14. McCarthy, K.L.; Underdahl, S.R.; Undi, M.; Becker, S.; Dahlen, C.R. Utilizing an electronic feeder to measure mineral and energy supplement intake in beef heifers grazing native range. Trans. Anim. Sci. 2019, 3, 1719-1723. [CrossRef]

15. Simanungkalit, G.; Hegarty, R.S.; Cowley, F.C.; McPhee, M.J. Evaluation of remote monitoring units for estimating body weight and supplement intake of grazing cattle. Animal 2020, 14, s332-s340. [CrossRef]

16. Hall, T.J.; McIvor, J.G.; Jones, P.; Smith, D.R.; Mayer, D.G. Comparison of stocking methods for beef production in northern Australia: Seasonal diet quality and composition. Rangeland J. 2017, 38, 553-567. [CrossRef]

17. Wickham, H.; François, R.; Henry, L.; Müller, K. dplyr: A Grammar of Data Manipulation, 0.8.5. 2020. Available online: https: / /CRAN.R-project.org/package=dplyr (accessed on 7 March 2021).

18. R Core Team. R: A Language and Environment for Statistical Computing; R Foundation for Statistical Computing: Vienna, Austria, 2020.

19. Kuznetsova, A.; Brockhoff, P.B.; Christensen, R.H.B. lmerTest package: Tests in linear mixed effects models. J. Stat. Softw. 2017, 82, 1-26. [CrossRef]

20. Williams, L.R.; Moore, S.T.; Bishop-Hurley, G.J.; Swain, D.L. A sensor-based solution to monitor grazing cattle drinking behaviour and water intake. Comput. Electron. Agric. 2020, 168, 105141. [CrossRef]

21. Dixon, R.M.; Anderson, A.; Petherick, J.C. Inclusion of cottonseed meal into loose mineral mix supplements increases the voluntary intake of the supplement by grazing heifers. Anim. Prod. Sci. 2017, 57, 315-319. [CrossRef]

22. Ruiz-Garcia, L.; Lunadei, L. The role of RFID in agriculture: Applications, limitations and challenges. Comput. Electron. Agric. 2011, 79, 42-50. [CrossRef]

23. Williams, L.R.; Fox, D.R.; Bishop-Hurley, G.J.; Swain, D.L. Use of radio frequency identification (RFID) technology to record grazing beef cattle water point use. Comput. Electron. Agric. 2019, 156, 193-202. [CrossRef]

24. Wallace, L.E.; Paterson, J.A.; Clark, R.; Harbac, M.; Kellom, A. Readability of thirteen different radio frequency identification ear tags by three different multi-panel reader systems for use in beef cattle. Prof. Anim. Sci. 2008, 24, 384-391. [CrossRef]

25. Schwartzkopf-Genswein, K.S.; Huisma, C.; McAllister, T.A. Validation of a radio frequency identification system for monitoring the feeding patterns of feedlot cattle. Livest. Prod. Sci. 1999, 60, 27-31. [CrossRef]

26. Sowell, B.F.; Mosley, J.C.; Bowman, J.G.P. Social behavior of grazing beef cattle: Implications for management. J. Anim. Sci. 2000, 77, 1-6. [CrossRef]

27. Tait, R.M.; Fisher, L.J. Variability in individual animal's intake of minerals offered free-choice to grazing ruminants. Anim. Feed. Sci. Technol. 1996, 62, 69-76. [CrossRef]

28. Kilgour, R.J. In pursuit of "normal": A review of the behaviour of cattle at pasture. Appl. Anim. Behav. Sci. 2012, 138, 1-11. [CrossRef]

29. Wesley, R.L.; Cibils, A.F.; Mulliniks, J.T.; Pollak, E.R.; Petersen, M.K.; Fredrickson, E.L. An assessment of behavioural syndromes in rangeland-raised beef cattle. Appl. Anim. Behav. Sci. 2012, 139, 183-194. [CrossRef]

30. Neave, H.W.; Weary, D.M.; Von Keyserlingk, M.A.G. Individual variability in feeding behaviour of domesticated ruminants. Animal 2018, 12, s419-s430. [CrossRef] [PubMed]

31. Vujović, V.; Maksimović, M. Raspberry Pi as a Wireless Sensor node: Performances and constraints. In Proceedings of the 2014 37th International Convention on Information and Communication Technology, Electronics and Microelectronics (MIPRO), Opatija, Croatia, 26-30 May 2014; pp. 1013-1018. 